\title{
Reaction Chemistry and Kinetics of Corn Stalk Pyrolysis without and with Ga/HZSM-5
}

Ben Huang a, Xinyue Xie a, Yang Yang ${ }^{\text {b }}$, Md. Maksudur Rahman ${ }^{\text {a }}$, Xingguang Zhang ${ }^{\mathrm{c}}$, Xi

$\mathrm{Yu}^{\mathrm{b}}$, Paula H. Blanco ${ }^{\mathrm{b}}$, Zhujun Dong ${ }^{\mathrm{a}}$, Yuqing Zhang ${ }^{\mathrm{d}}$, Anthony V. Bridgwater ${ }^{\mathrm{b}}$, Junmeng $\mathrm{Cai}^{\mathrm{a}, *}$

${ }^{\text {a }}$ Biomass Energy Engineering Research Center, Key Laboratory of Urban Agriculture (South) Ministry of Agriculture, School of Agriculture and Biology, Shanghai Jiao Tong University, 800 Dongchuan Road, P. R. China

${ }^{\mathrm{b}}$ Bioenergy Research Group, European Bioenergy Research Institute (EBRI), Aston University, Birmingham B4 7ET, UK

${ }^{c}$ College of Chemical Engineering, Nanjing Forestry University, 159 Longpan Road, Nanjing 210037, P. R. China

${ }^{\mathrm{d}}$ Aston Institute of Materials Research (AIMR), Aston University, Birmingham B4 7ET, UK Corresponding author: Junmeng Cai, Tel.: +86-34206624; E-mail: jmcai@ sjtu.edu.cn; Website: http://biofuels.sjtu.edu.cn. 


\section{Abstract:}

The bifunctional Ga/HZSM-

5 catalyst has been proven

having the capabiliity to

increase the selectivity of

aromatics production during

catalytic pyrolysis of furan

and woody biomass.

However, the reaction

chemistry and kinetics of

pyrolysis of herbaceous

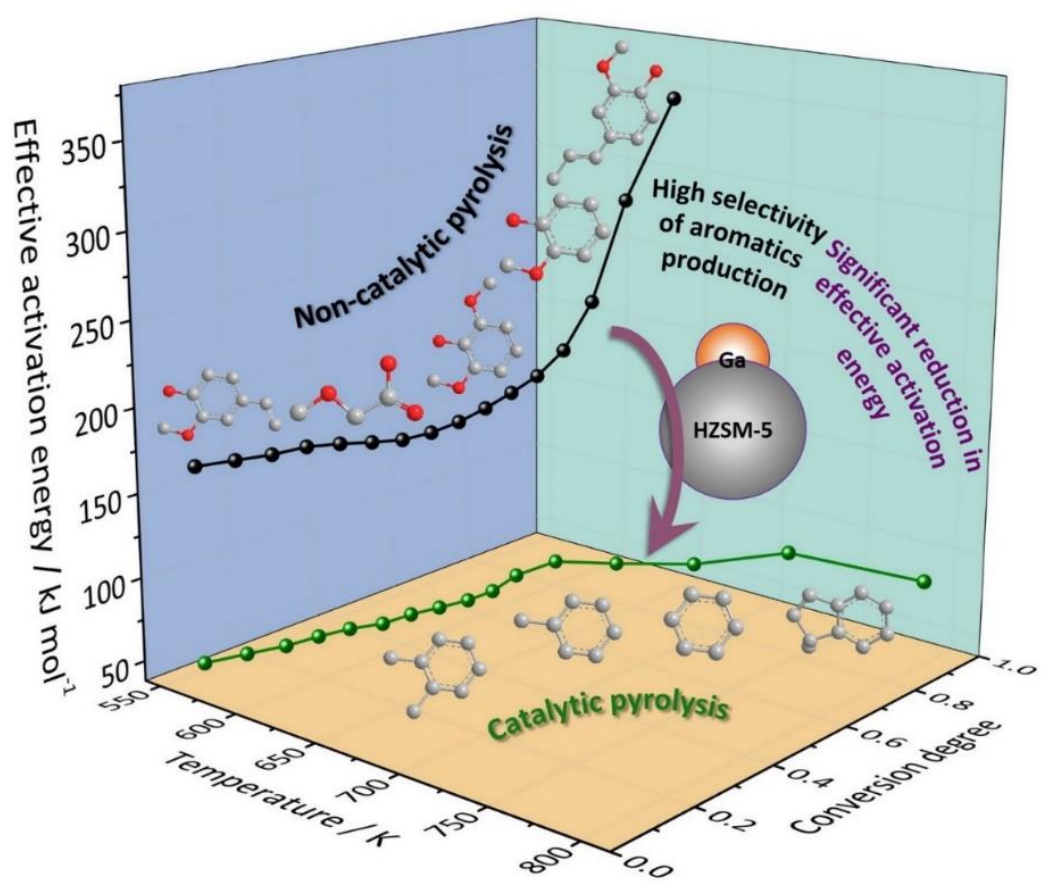

biomass promoted by Ga/HZSM-5 is rarely reported. Pyrolysis - gas chromatography / mass spectrometry (Py-GC/MS) analysis and nonisothermal thermogravimetric (TG) analysis at four heating rates were carried out to investigate the decomposition behavior and pyrolysis kinetics of corn stalk without and with Ga/HZSM-5. The effective activation energies for corn stalk pyrolysis were calculated by using the Friedman isoconversional method. The Py-GC/MS analysis results indicated that the Ga/HZSM-5 catalyst had a high selectivity towards producing the aromatic chemicals of xylene, toluene and benzene, whereas the major products from noncatalytic pyrolysis of corn stalk were oxygenated compounds. The presence of $\mathrm{Ga} / \mathrm{HZSM}-5$ could significantly reduce the effective activation energies of corn stalk pyrolysis from 159.9$352.4 \mathrm{~kJ} \mathrm{~mol}^{-1}$ to $41.6-99.8 \mathrm{~kJ} \mathrm{~mol}^{-1}$ in the conversion range of $0.10-0.85$.

Key words: Catalytic pyrolysis; Biomass; Kinetics; Isoconversional kinetic analysis; PyGC/MS; TG 


\section{Introduction}

The remarkable development of society and economy, industrialization of factory production, and rapid growth use of motor vehicles in the world have led to a significant increase in energy consumption, of which a large proportion (about 80\%) comes from petroleum-derived fuels [1]. Furthermore, the use of fossil fuels leads to the environmental issues such as global warming due to the emission of greenhouse gases or acid rain by releasing harmful gases (e.g., $\mathrm{NO}_{\mathrm{x}}$ and $\mathrm{SO}_{2}$ ) [2].

In view of these urgent issues in energy and environment, many countries including China (the world's largest greenhouse gas emitter) are taking substantial measures to promote a greater use of renewable energy resources to reduce the heavy dependence on fossil fuels [3]. Among existent renewable energy sources, biomass has attracted immense attention because it is a promising and cost-effective feedstock to produce clean and renewable biofuels $[4,5]$. Biomass can be exploited to produce biofuel, heat or chemicals via different conversion technologies. Among these technologies, pyrolysis can produce liquid fuels (pyrolysis oil) which is easy to handle and utilize, and it is relatively simple and inexpensive to deploy [6-9]. However, its overall efficacy suffers from the quality of pyrolysis oils due to the fact that they contain many undesirable components (such as high content of volatile acids, water and oxygenated compounds), which limits the applications of pyrolysis oil $[10,11]$. Therefore, the upgrading of pyrolysis oils is required before they are used as transport fuels or for clean chemicals [12, 13].

Catalytic pyrolysis, which incorporates catalyst within the pyrolysis of lignocellulosic biomass, is one of the most promising methods to improve the quality of pyrolysis oils. The presence of a catalyst in lignocellulosic biomass pyrolysis can significantly affect the thermal decomposition pathway of lignocellulosic biomass, product distribution (selectivity) and the yields of products $[14,15]$. Some studies on catalytic pyrolysis have focused on the operating 
parameters, biomass composition, catalyst type, catalytic activities, or selectivity of pyrolysis products $[16,17]$. However, few publications reported the catalytic pyrolysis kinetics of lignocellulosic biomass, which is fundamental to understand the corresponding mechanisms and improve the application and performance of biomass catalytic pyrolysis [18, 19]. Batista et al. [20] used thermogravimetric (TG) analysis to study the catalytic pyrolysis kinetics of coffee grounds waste. They found that there were some differences in the experimental curves between pyrolysis of biomass and biomass mixed with zeolites and, therefore, a single global reaction model could not accurately reproduce the experimental data. Bu et al. [21] used a second-order reaction model to describe the thermal decomposition kinetics of lignin with activated carbon as a catalyst. The results showed that the presence of the catalyst could lower the activation energy of lignin catalytic pyrolysis. Poddar et al. [22] used a lumped model to describe the pyrolysis kinetics of jute (a waste bio-packaging material) with different catalysts, and found that alumina was the best performing catalyst showing the highest pyrolysis oil yield and the lowest activation energy. $\mathrm{Li}$ et al. [23] studied the catalytic pyrolysis kinetics of industrial lignins (by-products of the pulp and paper industry) with HZSM-5 as a catalyst in a coupling of thermogravimetry and Fourier transform infrared spectroscopy (TG-FTIR) and used Kissinger's method to analyze the experimental data, resulting in activation energies of 104.3, 128.5, $169.0 \mathrm{~kJ} \mathrm{~mol}^{-1}$ for three sub-processes. Lu et al. [24] studied the catalytic pyrolysis kinetics of wheat straw and obtained that the presence of the bifunctional catalyst Ni-Mo$\mathrm{HUSY} / \gamma-\mathrm{Al}_{2} \mathrm{O}_{3}$ could noticeably reduce the activation energy from 207.1 to $168.6 \mathrm{~kJ} \mathrm{~mol}^{-1}$. Chandrasekaran et al. [25] investigated the catalytic pyrolysis of waste polyethylene over Yzeolite and the results showed a reduction in activation energy from 294 to $169 \mathrm{~kJ} \mathrm{~mol}^{-1}$. In the above-mentioned studies, the researchers used one or several activation energy values to describe the catalytic pyrolysis kinetic behaviors of biomasses. Given the fact that the catalytic pyrolysis of lignocellulosic biomass is a multi-step process, one or several activation energy 
values are insufficient to describe it [26].

Many studies suggested that complex solid reactions had a rather wide distribtuion in the activation energies [27]. The dependency of activation energy on the conversion degree computed by isoconversional methods manifests the activation energy distribution, which is helpful in exploring mechanisms and predicting kinetic behaviors for complex solid state reaction processes [28]. The isoconversional method suggested by Friedman is straightforward and most widely used because of its simplicity and high accuracy among common isoconversional methods [29]. The Friedman isoconversional method is sensitive to data noise, but the results can be improved by applying advanced smoothing methods [30].

The bifunctional Ga/HZSM-5 catalyst has been proven having the capability to increase the selectivity of aromatics production during catalytic pyrolysis of furan (a model biomass compound) [31] and woody biomass (e.g, pine [31] and poplar wood [32]). However, research findings regarding the catalytic pyrolysis of herbaceous biomass is still missing in the literature. This study comparatively investigates the selectivity of aromatics production during catalytic pyrolysis of corn stalk (a typical herbaceous biomass) over the promotion of $\mathrm{Ga} / \mathrm{HZSM}-5$ by means of the pyrolysis - gas chromatography / mass spectrometry (Py-GC/MS) analysis and studies the corresponding catalytic pyrolysis kinetics through the isoconversional kinetic analysis.

\section{Materials and experiments}

\subsection{Materials}

Corn stalk was chosen as the lignocellulosic biomass feedstock in this study considering its abundance in China (about 72 million tons per year). The samples were obtained from a farm located in Fujian Province. Prior to analysis, the samples were processed with a series of pretreatment including drying, grinding and sieving. The results of proximate, ultimate and 
compositional analyses and heating value together with the corresponding standard test methods are listed in Table $\mathbf{1 .}$ 
Table 1. Results of proximate, ultimate and composition analysis and heating value of corn stalk samples together with standard test methods

\begin{tabular}{|c|c|c|c|c|}
\hline Property & Item & Standard Test Method & Value & Basis of analysis \\
\hline \multirow[t]{5}{*}{ Proximate analysis } & Moisture & ASTM E1756-08. Standard Test Method for Determination of Total Solids in Biomass & 16.7 wt.\% & As received basis \\
\hline & Ash & ASTM E1755-01. Standard Test Method for Ash in Biomass & 13.3 wt. $\%$ & \\
\hline & Volatile & ASTM E872 -82. Standard Test Method for Volatile Matter in the Analysis of Particulate Wood Fuels & 56.0 wt. $\%$ & \\
\hline & matter & & & \\
\hline & Fixed carbon & Calculated by difference & 14.0 wt. $\%$ & \\
\hline \multirow[t]{4}{*}{ Ultimate analysis } & Carbon & ASTM E777. Standard Test Method for Carbon and Hydrogen in the Analysis Sample of Refuse-Derived Fuel & 48.8 wt. $\%$ & Dry ash free basis \\
\hline & Hydrogen & & 6.5 wt. $\%$ & \\
\hline & Nitrogen & ASTM E778-15. Standard Test Methods for Nitrogen in Refuse-Derived Fuel Analysis Samples & 3.7 wt. $\%$ & \\
\hline & Oxygen & Calculated by difference & 41.0 wt. $\%$ & \\
\hline \multirow{4}{*}{$\begin{array}{l}\text { Compositional } \\
\text { analysis }\end{array}$} & Cellulose & NREL/TP-510-42618. A. Sluiter, B. Hames, R. Ruiz, C. Scarlata, J. Sluiter, D. Templeton, D. Crocker. & 32.6 wt. $\%$ & Dry ash free basis \\
\hline & Hemicellulose & Determination of structural carbohydrates and lignin in biomass & 36.4 wt. $\%$ & \\
\hline & Lignin & & 18.2 wt. $\%$ & \\
\hline & Others & & 12.7 wt. $\%$ & \\
\hline \multirow[t]{2}{*}{ Higher heating value } & & ASTM E711-87. Standard Test Method for Gross Calorific Value of Refuse-Derived Fuel by the Bomb & 16.5 MJ kg-1 & Dry basis \\
\hline & & Calorimeter & & \\
\hline
\end{tabular}


The bifunctional Ga/HZSM-5 catalyst used in this study was prepared following the method described by Cheng and co-workers [31] with an ion exchange method, where $1 \mathrm{~g}$ of HZSM-5 (Zeolyst Int, CBV 3024E, $\mathrm{SiO}_{2} / \mathrm{Al}_{2} \mathrm{O}_{3}=30$ ) was refluxed in $100 \mathrm{~mL}$ of an aqueous solution of $\mathrm{Ga}\left(\mathrm{NO}_{3}\right)_{3}(0.010 \mathrm{M}$, Sigma-Aldrich, $99.9 \%)$ at $343 \mathrm{~K}\left(70{ }^{\circ} \mathrm{C}\right)$ for $12 \mathrm{~h}$. After the ion exchange, the resulting gallium $(\mathrm{Ga})$ solution was filtered to obtain the solid catalysts, and these catalysts were dried at $383 \mathrm{~K}\left(110{ }^{\circ} \mathrm{C}\right)$ and then calcined in air at $823 \mathrm{~K}\left(550{ }^{\circ} \mathrm{C}\right)$ for $2 \mathrm{~h}$. The Ga content in each catalyst was determined by the inductively coupled plasma (ICP) analysis performed by Galbraith Laboratories (Knoxville, Tennessee, USA): $\mathrm{SiO}_{2} / \mathrm{Al}_{2} \mathrm{O}_{3}=30$, $\mathrm{SiO}_{2} / \mathrm{Ga}_{2} \mathrm{O}_{3}=68$, and $\mathrm{SiO}_{2} /\left(\mathrm{Al}_{2} \mathrm{O}_{3}+\mathrm{Ga}_{2} \mathrm{O}_{3}\right)=21$. The Brönsted acids and Lewis acids were analyzed in a thermogravimetric analysis-mass spectrometry (TG-MS) coupled with the $\mathrm{NH}_{3}$ and isopropylamine (IPA) - temperature programmed desorption (TPD). A Brönsted acid density of 0.23 a.u. was obtained by IPA-TPD (recorded $\mathrm{m} / \mathrm{z}=41$ (propylene)). The total acidity was achieved by $\mathrm{NH}_{3}$-TPD (recorded $\mathrm{m} / \mathrm{z}$ value $=17$ ), the Lewis acidity was calculated to be 0.43 a.u., and the ratio between Brönsted acid and Lewis acids was 0.35.

Both the corn stalk and catalyst samples were sieved (80 mesh) before mixing. Ground reactants were prepared by evenly mixing the corn stalk feedstock and the Ga/HZSM-5 catalyst with a catalyst to biomass ratio of 10 .

\subsection{Pyrolysis - gas chromatography / mass spectrometry analysis}

The Py-GC/MS analysis of corn stalk without and with Ga/HZSM-5 was carried out in a platinum coil pyroprobe (Pyroprobe 5200, CDS, Oxford, PA) connected to a PerkinElmer Clarus 680 GC and Clarus 600S MS. The separation was performed using a PerkinElmer Elite1701 column. Samples of $2 \mathrm{mg} \pm 0.25 \mathrm{mg}$ of corn stalk and mixture of corn stalk and catalyst were placed in a $20 \mathrm{~mm}$ quartz tube and fixed using wool. Pyrolysis was carried out at $773 \mathrm{~K}$ $\left(500{ }^{\circ} \mathrm{C}\right)$ with a heating rate of $500 \mathrm{~K} \mathrm{~s}^{-1}$ and pyrolysis time of $30 \mathrm{~s}$. The resulting pyrolysis 
vapor was sent to the GC column with a helium flow through a heated transfer line (maintained at $\left.583 \mathrm{~K}\left(310^{\circ} \mathrm{C}\right)\right)$. The $\mathrm{GC}$ oven was held at $318 \mathrm{~K}\left(45^{\circ} \mathrm{C}\right)$ for $2.5 \mathrm{~min}$ and then ramped to 523 $\mathrm{K}\left(250{ }^{\circ} \mathrm{C}\right)$ at a heating rate of $2.5 \mathrm{~K} \mathrm{~min}^{-1}$. The mass spectra was obtained for molecular mass range of $\mathrm{m} / \mathrm{z}=45-300$. Assignments of the peaks in the chromatogram were made using the NIST2005 MS library.

\subsection{Thermogravimetric analysis}

The pyrolysis kinetic analysis of corn stalk without and with Ga/HZSM-5 was performed in a thermogravimetric analyzer (Pyris 1 TGA, PerkinElmer, USA). High-purity nitrogen was used as carrier gas at a flow rate of $20 \mathrm{~mL} \mathrm{~min}^{-1}$. The samples of corn stalk, catalyst, and corn stalk mixed with catalyst were placed in $\mathrm{Al}_{2} \mathrm{O}_{3}$ crucibles and pyrolyzed in duplicate at the heating rates of $5,10,20$, and $40 \mathrm{~K} \mathrm{~min}^{-1}$. Blank runs at the respective heating rates were performed and their results were used to correct the results of pyrolysis sample runs to remove any instrument artifact. For each heating rate, the TG oven hold at $378 \mathrm{~K}\left(105{ }^{\circ} \mathrm{C}\right)$ for $30 \mathrm{~min}$ in order to remove the water contained in the sample. After the experiments, the masses of the samples with the time and temperature were obtained.

\section{Isoconversional kinetic analysis}

The Friedman isoconversional method has been selected for the main reasons mentioned above. On the basis of our previous case study of processing TG data for isoconversional kinetic analysis [29], the main actions are summarized in Figure 1. 


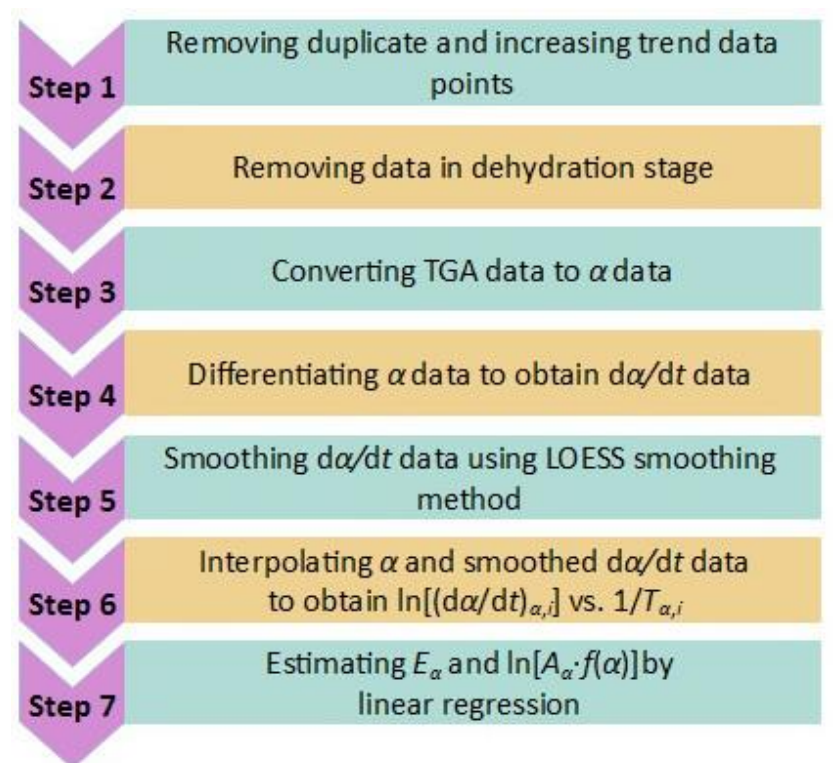

Figure 1. Flow diagram of processing TG data for isoconversional kinetic analysis

At first both duplicate and increasing trend data points included in experimental TG data were removed. Then the dehydration stage was removed according to the ASTM Standard E1131 since the mechanism of water evaporation in the dehydration stage is different from the decomposition of lignocellulosic components contained in biomass [29]. The mass loss data sets were normalized and the degree of conversion was obtained from Equation (1):

$$
\alpha(t)=\frac{m_{0}-m(t)}{m_{0}-m_{f}}
$$

where $\alpha$ is the degree of conversion, $t$ is the time, $m_{0}$ is the mass at the temperature $T_{0}, m(t)$ is the mass at the time $t$, and $m_{f}$ is the final mass.

The conversion values of corn stalk catalytic pyrolysis $\left(\alpha_{\text {bio }}\right)$ were calculated from the conversion data of the catalyst $\left(\alpha_{\text {cat }}\right)$ and the mixture of corn stalk and catalyst $\left(\alpha_{\text {mix }}\right)$ :

$$
\begin{gathered}
m_{\text {cat }}(t)=m_{0, \text { cat }}-\alpha_{\text {cat }}(t) \cdot\left(m_{0, \text { cat }}-m_{f, \text { cat }}\right) \\
m_{\text {mix }}(t)=m_{0, \text { mix }}-\alpha_{\text {mix }}(t) \cdot\left(m_{0, \text { mix }}-m_{f, \text { mix }}\right)
\end{gathered}
$$

According to Equations (2) and (3), the conversion data of catalytic pyrolysis of corn stalk 
were obtained:

$$
\begin{aligned}
\alpha_{\text {bio }}(t) & =\frac{m_{0, \text { bio }}-m_{\text {bio }}(t)}{m_{0, \text { bio }}-m_{f, \text { bio }}} \\
= & \frac{\left(m_{0, \text { mix }}-m_{\text {mix }}(t)\right)-\left(m_{0, \text { cat }}-m_{\text {cat }}(t)\right)}{\left(m_{0, \text { mix }}-m_{f, \text { mix }}\right)-\left(m_{0, \text { cat }}-m_{f, \text { cat }}\right)} \\
= & \frac{\alpha_{\text {mix }}(t) \cdot\left(m_{0, \text { mix }}-m_{f, \text { mix }}\right)-\alpha_{\text {cat }}(t) \cdot\left(m_{0, \text { cat }}-m_{f, \text { cat }}\right)}{\left(m_{0, \text { mix }}-m_{f, \text { mix }}\right)-\left(m_{0, \text { cat }}-m_{f, \text { cat }}\right)} \\
= & \frac{\alpha_{\text {mix }}(t) \cdot\left(1-w_{f, \text { mix }}\right)-\alpha_{\text {cat }}(t) \cdot\left(1-w_{f, \text { cat }}\right) r_{\text {cat }}}{\left(1-w_{f, \text { mix }}\right)-\left(1-w_{f, \text { cat }}\right) r_{\text {cat }}}
\end{aligned}
$$

In the above equations, the subscripts cat, bio and mix represent the values related on catalyst, corn stalk and their mixture, respectively. The fraction of catalyst in the mixture of corn stalk and catalyst was given by $r_{\text {cat }}=m_{0, \text { cat }} / m_{0, \text { mix }}$, whereas the ratio between the initial and final mass of the catalyst $w_{f, \text { cat }}=m_{f, \text { cat }} / m_{0, \text { cat }}$ was obtained from the TG data of the catalyst. The ratio between the initial and final mass of the corn stalk and catalyst mixture was obtained by using $w_{f, \text { mix }}=m_{f, \text { mix }} / m_{0, \text { mix }}$.

The derivative conversion data required in the implementation of the Friedman isoconversional method was obtained from the numerical differentiation of the conversion data by using the central difference method [29].

$$
\left(\frac{\mathrm{d} \alpha}{\mathrm{d} t}\right)_{i}= \begin{cases}\frac{\alpha_{i+1}-\alpha_{i}}{t_{i+1}-t_{i}} & \text { for start point } \\ \frac{1}{2} \frac{\alpha_{i}-\alpha_{i-1}}{t_{i}-t_{i-1}}+\frac{1}{2} \frac{\alpha_{i+1}-\alpha_{i}}{t_{i+1}-t_{i}} & \text { for intermediate points } \\ \frac{\alpha_{i}-\alpha_{i-1}}{t_{i}-t_{i-1}} & \text { for end point }\end{cases}
$$

The derivative conversion data usually contains data noises, which causes the results being numerically unstable $[33,34]$. Hence, in order to reduce the impact of data noises on further analyses, data smoothing is required [35]. In this study, the locally weighted scatterplot 
smoothing method coupled with the corrected AIC smoothing parameter selection method was used for the smoothing of the derivative data [30].

The Friedman isoconversional method is based on the general kinetic equation (Equation (6)) and the isoconversional principle (Equation (7)) that defines the activation energy through the derivative of the conversion rate data corresponding to a given conversion [36]:

$$
\begin{gathered}
\frac{\mathrm{d} \alpha}{\mathrm{d} t}=A e^{-E / R T} f(\alpha) \\
E_{\alpha}=-R\left[\frac{\partial \ln (\mathrm{d} \alpha / \mathrm{d} t)}{\partial(1 / T)}\right]_{\alpha}
\end{gathered}
$$

where $A$ is the frequency factor, $E$ is the activation energy, $R$ is the universal gas constant, $f(\alpha)$ is the differential conversion function and the subscript $\alpha$ designates a given degree of conversion.

The basic equation of the Friedman isoconversional method is then obtained by rearranging Equations (6) and (7) as follows:

$$
\ln \left(\left.\frac{\mathrm{d} \alpha}{\mathrm{d} t}\right|_{\alpha, i}\right)=\ln \left[A_{\alpha} f(\alpha)\right]-\frac{E_{\alpha}}{R T_{\alpha, i}}
$$

where the subscript $i$ represents a given value of heating rate. For a given $\alpha$, plotting $\ln \left[(\mathrm{d} \alpha / \mathrm{d} t)_{\alpha, i}\right]$ versus $\left(1 / T_{\alpha, i}\right)$ produces a line. The $E_{\alpha}$ and $\ln \left[A_{\alpha} \cdot f(\alpha)\right]$ values can be determined by the slope and intercept of the line, respectively. Repeating this procedure for different $\alpha$ values obtains the $E_{\alpha}$ and $\ln \left[A_{\alpha} \cdot f(\alpha)\right]$ dependencies. Detailed information can found in our previous paper [29].

Based on the obtained $E_{\alpha}$ and $\ln \left[A_{\alpha} \cdot f(\alpha)\right]$ values at various $\alpha$, the kinetic process can be reconstructed by means of the classical fourth-order Runge-Kutta method. 


\section{Results and discussion}

The Py-GC/MS chromatograms of corn stalk pyrolysis without and with Ga/HZSM-5 at $500{ }^{\circ} \mathrm{C}$ with pyrolysis time of $30 \mathrm{~s}$ are illustrated in Figure 2. The main pyrolysis products identified from the Py-GC/MS chromatograms for corn stalk pyrolysis without and with Ga/HZSM-5 are listed in Supplementary Material Tables S1 and S2, respectively. The relative yields of the products were also calculated, which corresponds to the respective relative peak area among all of the detected peaks.

Various oxygenated compounds, prominently phenolic compounds and acids were produced from the non-catalytic pyrolysis of corn stalk, as depicted in Figure 2(a). The major phenolic compounds identified from the non-catalytic pyrolysis of corn stalk were 2-methoxy4-vinylphenol, 2,6-dimethoxyphenol, guaiacol and isoeugenol. Additionally, the most abundant acid detected was 2-methoxyacetic acid. The formation of phenolic compounds has been attributed to the decomposition of lignin according to previous studies [37, 38], whereas the production of acids could be related to the cleavages of carbon-carbon bonds in glucose units of cellulose [39].

On the other hand, it was observed that the use of Ga/HZSM-5 significantly changed the trends in the Py-GC/MS chromatograms (Figure 2(b)). The identified compounds in the catalytic pyrolysis were totally different from those obtained for the non-catalytic run where the yields of the oxygenated hydrocarbons were significantly reduced. The major identified compounds through catalytic conversion were aromatic hydrocarbons, prominently xylene, toluene and benzene, whereas the most abundant oxygenated compound was furan. These results revealed the Ga/HZSM-5 catalyst increased selectivity for the production of aromatic compounds during the catalytic pyrolysis of corn stalk (herbaceous biomass).

A proposed reaction pathway for pyrolysis products of corn stalk to aromatic compounds over Ga/HZSM-5 is shown in Figure 3. The mixture of chemical compounds produced during 
the pyrolysis of corn stalk resulted from the thermal decomposition of biomass biopolymers (e.g., hemicellulose, cellulose and lignin) into oxygenated compounds [40]. These intermediate oxygenates then diffused into the pore structure of the catalyst, where large molecules found in the pyrolysis products were broken down to produce smaller hydrocarbon fragments forming a "hydrocarbon pool" [41]. Monoaromatic compounds could have been produced due to the protonation, cyclization, dehydrogenation and aromatization functionalities of this hydrocarbon pool [32]. Furthermore, monoaromatic compounds could also react with other oxygenated compounds, leading to the production of polyaromatics [42]. Meanwhile, the Ga ions promoted demethylation, dehydration and aromatization functionalities, finally increasing the production of aromatic compounds (Figure 3) [41, 43, 44]. 

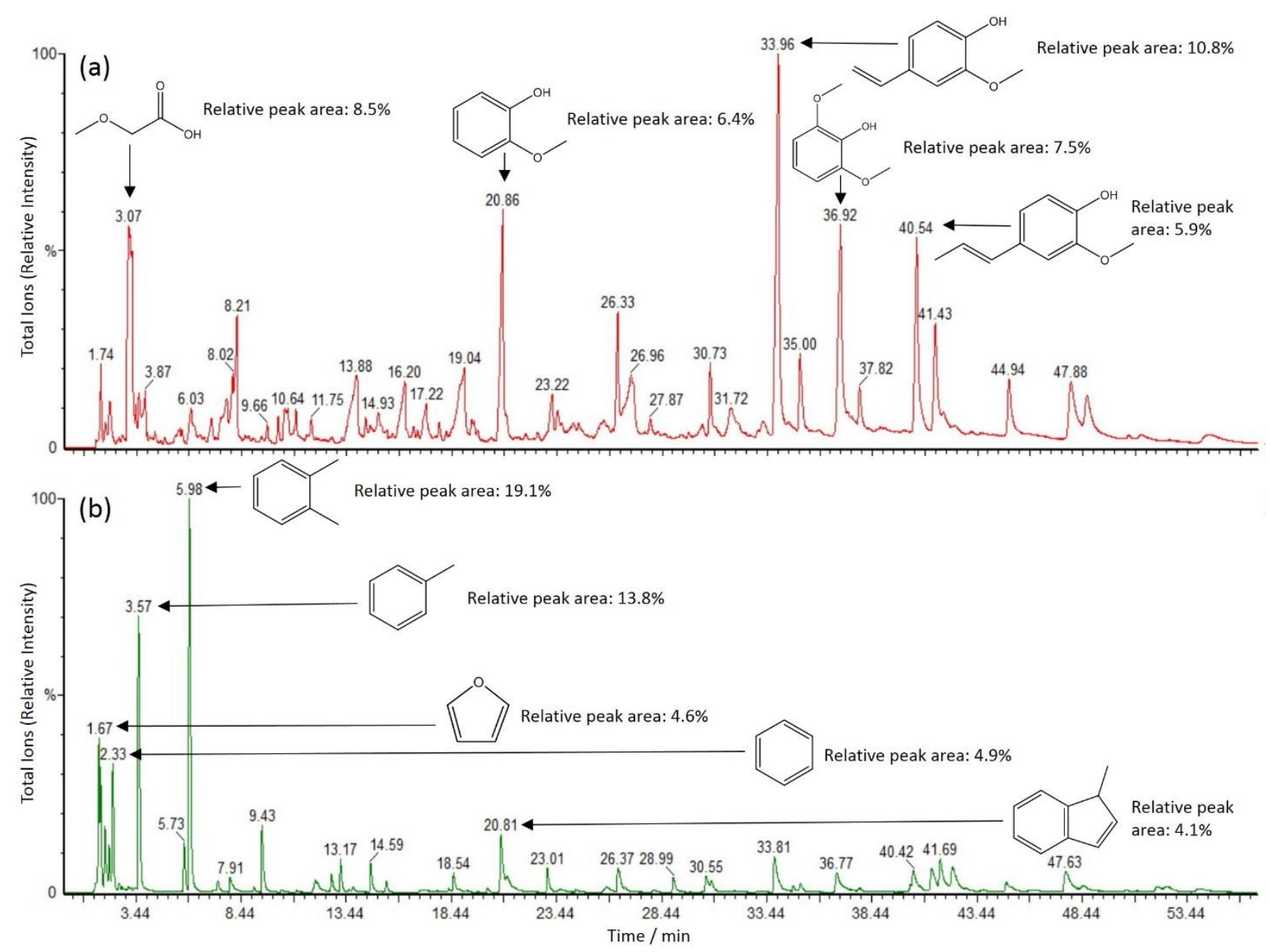

Figure 2. Py-GC/MS chromatograms for products from corn stalk pyrolysis (a) without and (b) with Ga/HZMM-5 (pyrolysis condition: $500{ }^{\circ} \mathrm{C}$ and $30 \mathrm{~s}$ ) 


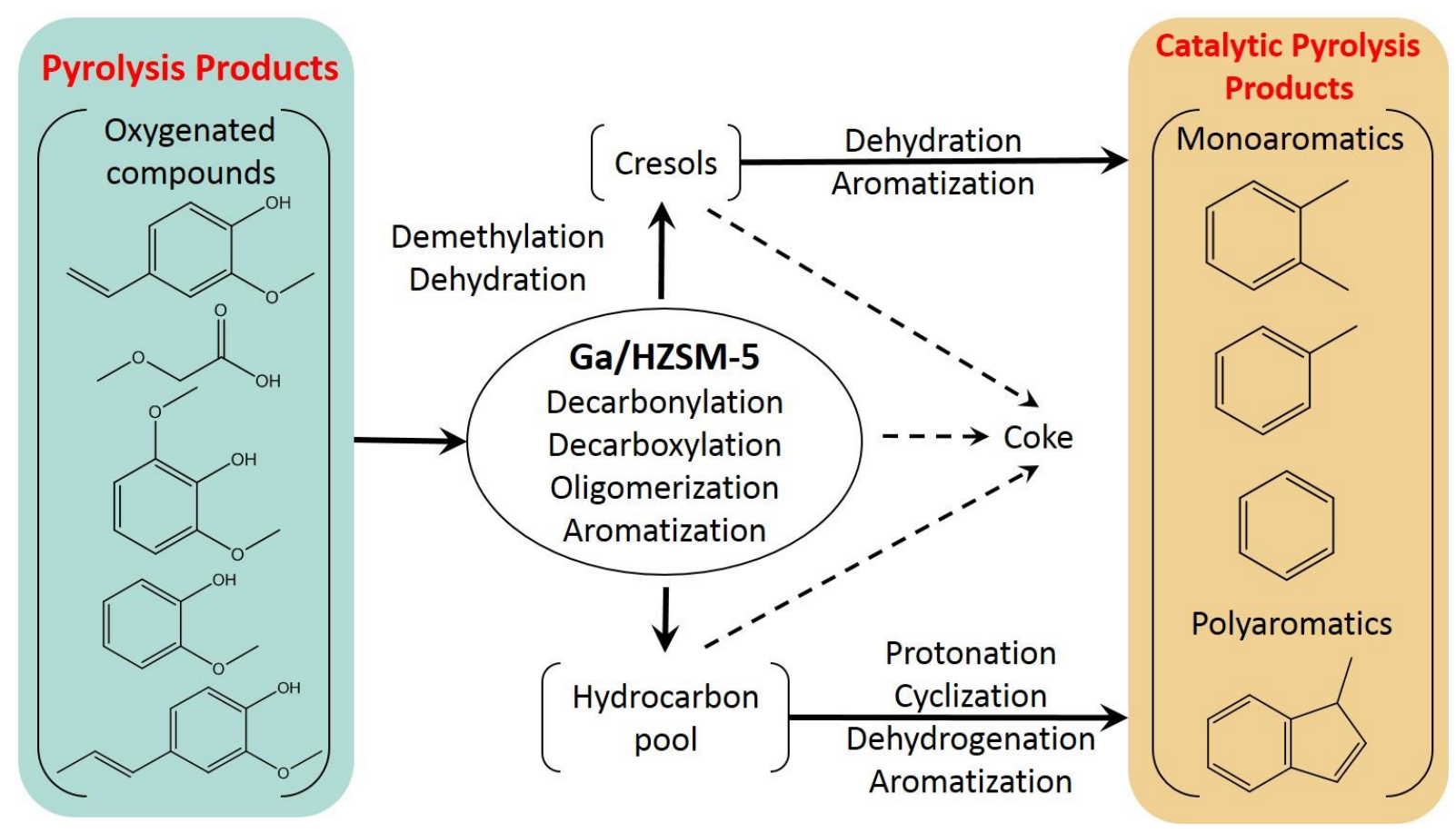

Figure 3. Proposed reaction pathway for pyrolysis products of corn stalk to aromatic compounds over $\mathrm{Ga} / \mathrm{HZSM}-5$

Figures 4 and 5 show the conversion and derivative conversion curves of corn stalk pyrolysis without and with Ga/HZSM-5 at different heating rates. From Figure 4, it was observed that the use of Ga/HZSM-5 reduced the conversion rate. Also from Figure 5, it was found that the conversion rate was reduced during catalytic conversion and that the derivative conversion curve was slightly shifted up the temperature scale when compared with the noncatalytic conversion curves. This behavior was attributed to the high catalyst and substrate ratio of $10: 1$, as the catalyst was surrounding the biomass sample. When the temperature was high enough $\left(>250^{\circ} \mathrm{C}\right)$, the biomass sample started to decompose into the pyrolysis vapor and char, and then the pyrolysis vapor passed through catalysts. In the instant contact between the pyrolysis vapor and the catalyst, the pyrolysis intermediates were converted into aromatic hydrocarbons [45]. The diffusional resistances became predominant for the catalysts' micropores, which could lower the releasing speed of the pyrolysis volatile products in comparison 
to non-catalytic pyrolysis. Similar observations were reported during the catalytic pyrolysis of polypropylene over nanocrystalline HZSM-5 [46] and the catalytic pyrolysis of waste LDPE over ZSM-5 [47]. Therefore, the releasing of the pyrolysis volatiles required longer time with the presence of the Ga/HZSM-5 catalyst than non-catalytic pyrolysis (Figure 4), and the production rate of pyrolysis oil could be reduced during catalytic conversion (Figure 5).
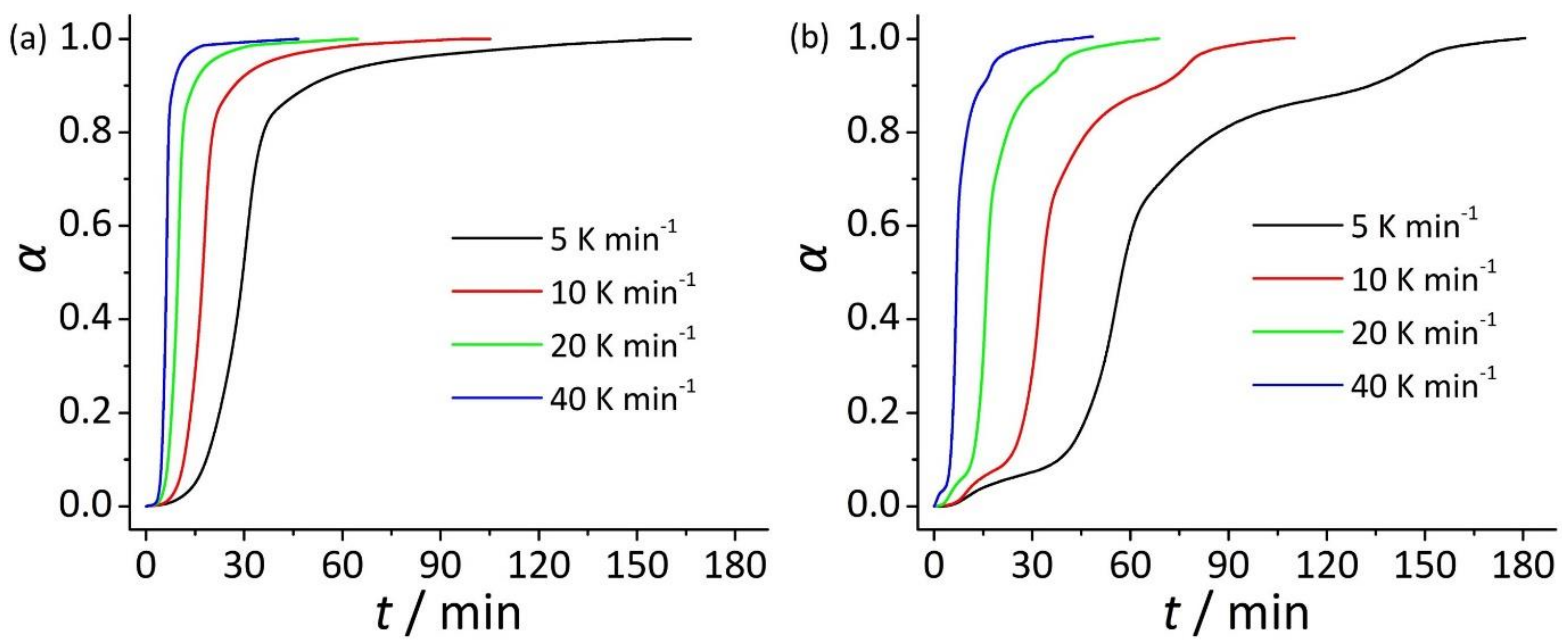

Figure 4. Conversion curves of corn stalk pyrolysis (a) without and (b) with Ga/HZSM-5 at various heating rates
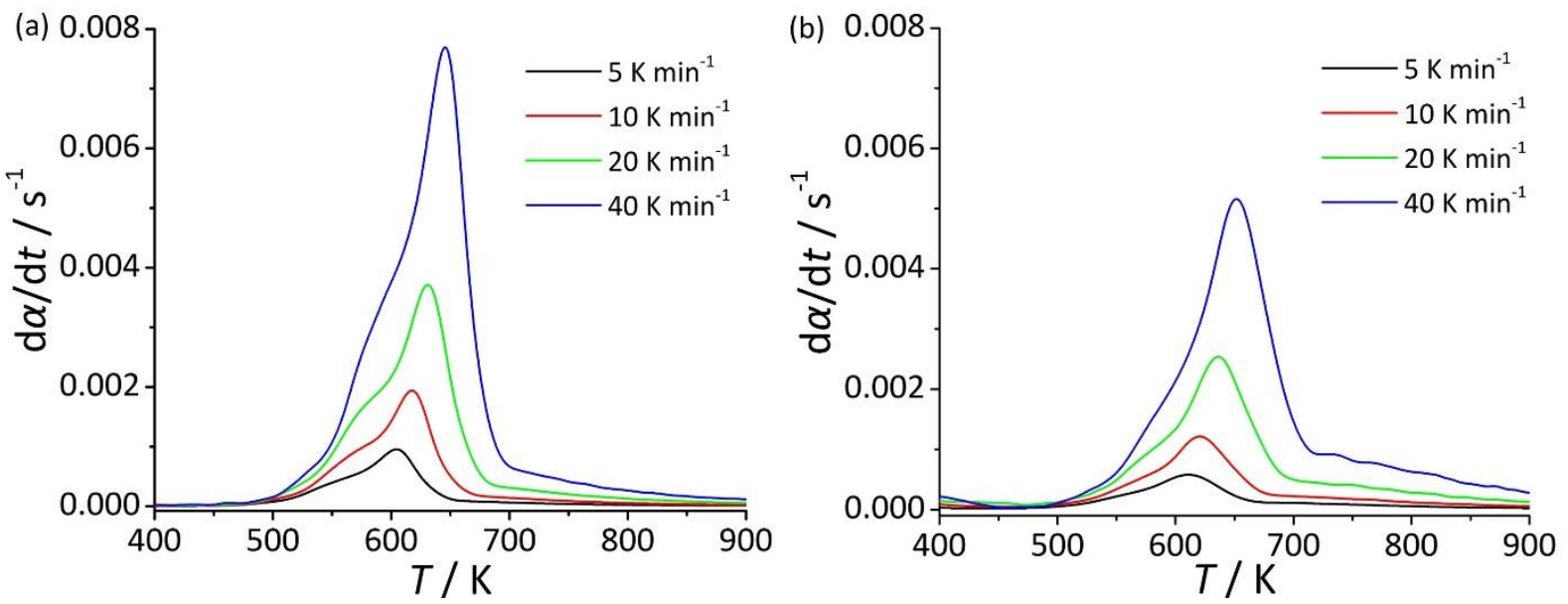

Figure 5. Derivative conversion curves of corn stalk pyrolysis (a) without and (b) with Ga/HZSM-5 at various heating rates 
By using the Friedman differential isoconversional method, the isoconversional plots at selected conversion values (0.10:0.05:0.85) for corn stalk pyrolysis without and with Ga/HZSM-5 were shown in Figure 6. It was observed that perfect linear relationships were obtained with correlation coefficient values greater than 0.98 for all the conversions. Based on the linear fitting, the dependencies of $E_{\alpha}$ and $\ln \left[A_{\alpha} \cdot f(\alpha)\right]$ on $\alpha$ for corn stalk pyrolysis without and with Ga/HZSM-5 were determined as shown in Figure 7.
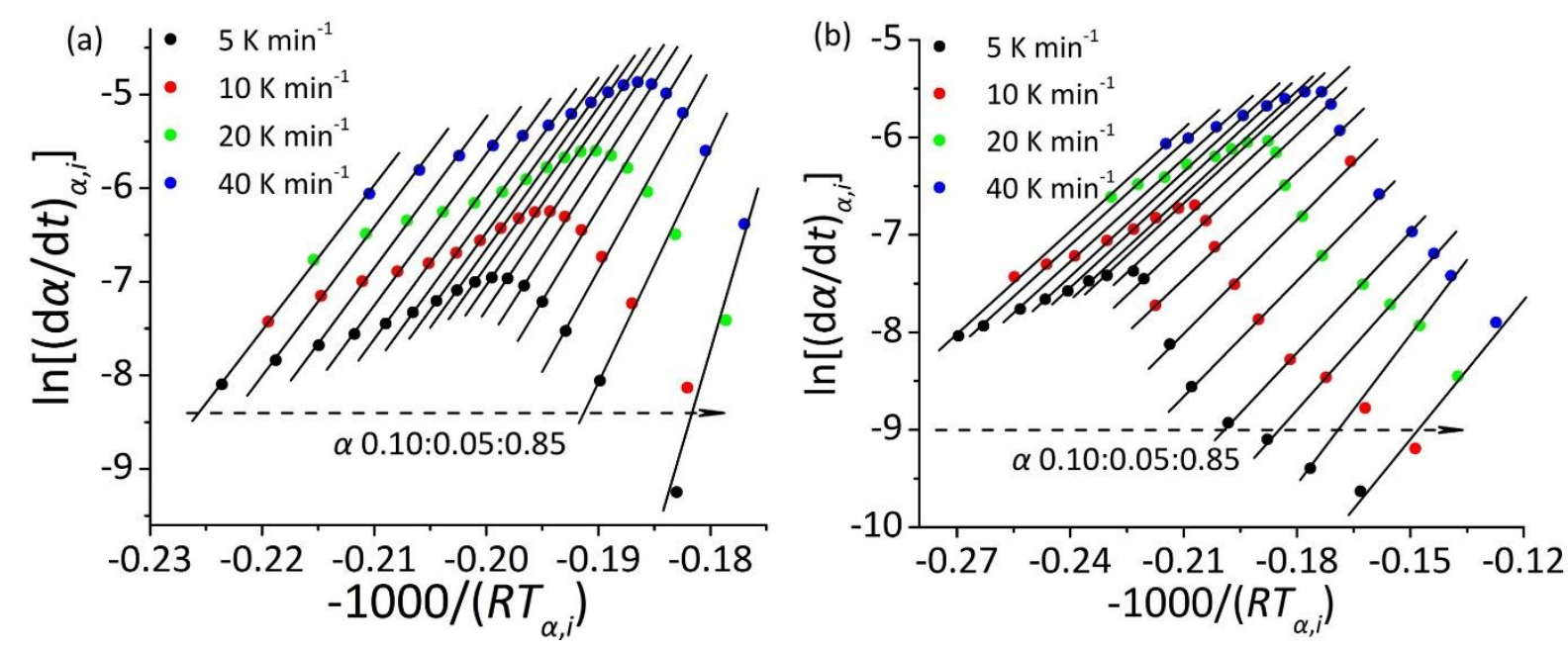

Figure 6. Friedman isoconversional plots at selected conversion degrees for corn stalk pyrolysis (a) without and (b) with Ga/HZSM-5
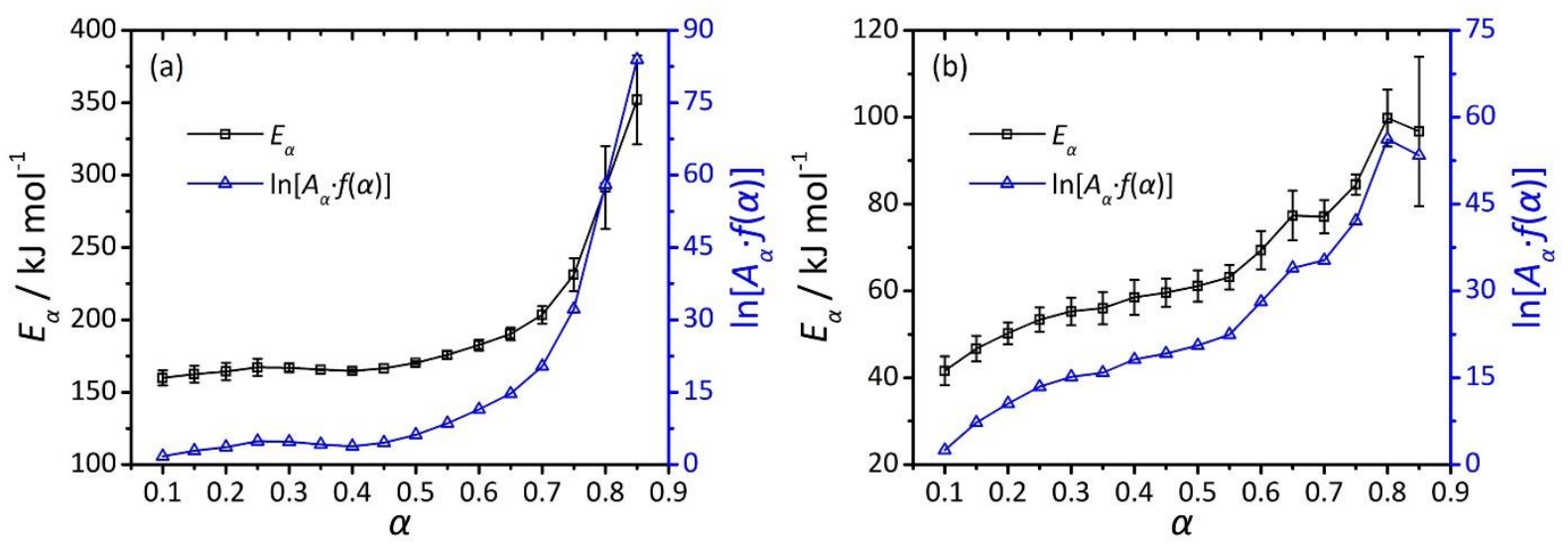

Figure 7. $E_{\alpha}$ and $\ln \left[A_{\alpha} \cdot f(\alpha)\right]$ as a function of $\alpha$ for corn stalk pyrolysis (a) without and (b) with

\section{$\mathrm{Ga} / \mathrm{HZSM}-5$}


From Figure 7, it can be observed that $E_{\alpha}$ and $\ln \left[A_{\alpha} \cdot f(\alpha)\right]$ significantly depend on $\alpha$ for corn stalk pyrolysis without and with Ga/HZSM-5. For the non-catalytic trend, it was observed that initially (1) $E_{\alpha}$ gradually increased from 159.9 to $175.9 \mathrm{~kJ} \mathrm{~mol}^{-1}$ when $\alpha$ increased from 0.10 to 0.55 ; and then (2) $E_{\alpha}$ sharply increased from 175.9 to $352.4 \mathrm{~kJ} \mathrm{~mol}^{-1}$ in the $\alpha$ range of $0.55 \leq \alpha \leq 0.85$. Corn stalk is a typical lignocellulosic biomass and its thermal decomposition via pyrolysis involves multistep processes. The effective activation energy of corn stalk pyrolysis is the collective parameter linked to the activation energies of its lignocellulosic components [48]. A similar trend of the $E_{\alpha}$ dependency can be found during the pyrolysis of other lignocellulosic biomasses $[28,49,50]$. For example, $E_{\alpha}$ for the pyrolysis of eucalyptus wood ranged from 150 to $215 \mathrm{~kJ} \mathrm{~mol}^{-1}$ when $\alpha$ increased from 0.05 to 0.79 ) [28]. For corn stalk catalytic pyrolysis, it was obtained that initially (1) in the $\alpha$ range of 0.10 to $0.55, E_{\alpha}$ slowly increased as a function of $\alpha\left(41.6 \mathrm{~kJ} \mathrm{~mol}^{-1} \leq E_{\alpha} \leq 63.2 \mathrm{~kJ} \mathrm{~mol}^{-1}\right)$; then (2) $E_{\alpha}$ sharply increased from 63.2 to $99.8 \mathrm{~kJ} \mathrm{~mol}^{-1}$ in the $\alpha$ range of $0.55 \leq \alpha \leq 0.80$; and finally (3) $E_{\alpha}$ gradually decreased from 99.8 to $96.7 \mathrm{~kJ} \mathrm{~mol}^{-1}$ when $\alpha$ ranges from 0.80 to 0.85 . This $E_{\alpha}$ dependency for corn stalk pyrolysis over Ga/HZSM-5 was similar to that for the catalytic pyrolysis of fir wood over various inorganic catalysts (e.g., $\mathrm{CuO}, \mathrm{TiO}_{2}, \mathrm{MnO}$ and $\mathrm{MoO}_{2}$ ) [51]. Figure 7 indicates that the effective activation energies for the catalytic pyrolysis of corn stalk over Ga/HZSM-5 were 59.3-74.0\% lower than those for the non-catalytic pyrolysis. The Ga/HZSM-5 catalyst had much better performance compared to the activation energies using other catalysts. For example, the activation energy for catalytic pyrolysis of wheat straw with the $\mathrm{Ni}-\mathrm{Mo}-\mathrm{HUSY} / \gamma-\mathrm{Al}_{2} \mathrm{O}_{3}$ catalyst was $18.6 \%$ lower than that for non-catalytic pyrolysis [24], and the activation energy for catalytic pyrolysis of waste polyethylene over Y-zeolite was $42.5 \%$ lower than that for noncatalytic pyrolysis [25].

Figure 8 shows the experimental data and the curves calculated from the obtained $E_{\alpha}$ and 
$\ln \left[A_{\alpha} \cdot f(\alpha)\right]$ values for corn stalk pyrolysis without and with $\mathrm{Ga} / \mathrm{HZSM}-5$. The results showed that the $E_{\alpha}$ and $\ln \left[A_{\alpha} \cdot f(\alpha)\right]$ values well matched the prediction of experimental kinetic data, which revealed that the isoconversional kinetic calculations were effective and the effective activation energies were accurate.
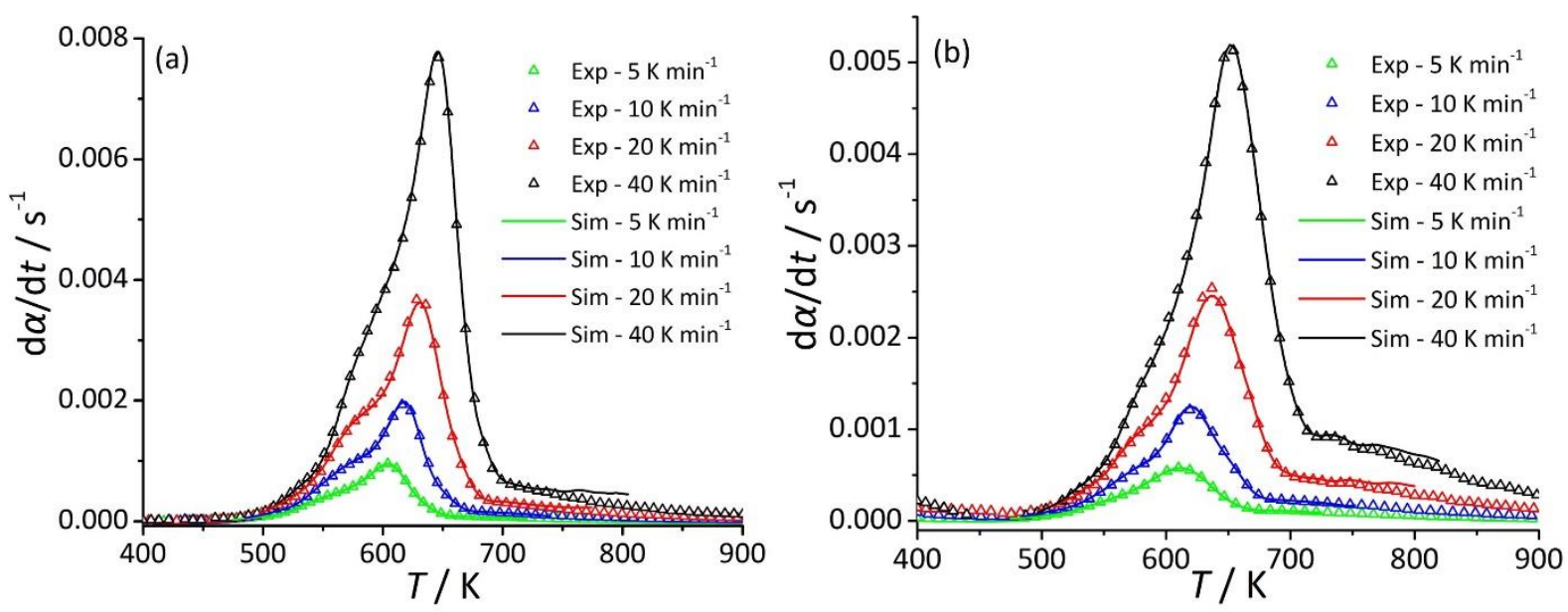

Figure 8. Comparison between experimental data and curves calculated from obtained kinetic parameters for corn stalk pyrolysis (a) without and (b) with catalyst

\section{Conclusions}

The analytical pyrolysis and kinetic analysis of corn stalk pyrolysis without and with the promotion of $\mathrm{Ga} / \mathrm{HZSM}-5$ catalyst were performed. The non-catalytic pyrolysis of corn stalk produced various oxygenated compounds including phenolic compounds and organic acids. Those oxygenated intermediates can be effectively converted into aromatic compounds (especially xylene, toluene, and benzene) when using Ga/HZSM-5 as a catalyst. The effective activation energies for corn stalk pyrolysis without and with $\mathrm{Ga} / \mathrm{HZSM}-5$ were determined by using the Friedman differential isoconversional kinetic method. The effective activation energies significantly varied with the conversion degree for both non-catalytic (159.9-352.4 kJ $\mathrm{mol}^{-1}$ in the conversion range of $\left.0.10-0.85\right)$ and catalytic $\left(41.6-99.8 \mathrm{~kJ} \mathrm{~mol}^{-1}\right.$ in the conversion range of $0.10-0.85)$ pyrolysis. The effective activation energies for the catalytic pyrolysis of 
corn stalk over Ga/HZSM-5 were 59.3-74.0\% lower than those required for than non-catalytic pyrolysis of corn stalk.

\section{Acknowledgements}

Junmeng Cai and Yuqing Zhang acknowledge the financial support from the GCRF Networking Grant (Project No.: GCRFNG\100203; Project Title: Pyrolysis of Municipal Organic Waste for Renewable Road Construction Materials). The authors acknowledge Mr. Yang Yu, Analyst in the Nielsen Company (Shanghai) Limited, for his help in TG, and Dr. Daniel Nowakowski, EBRI Laboratory Manager, for his help in Py-GC/MS analysis.

\section{References}

1. Escobar JC, Lora ES, Venturini OJ, Yáñez EE, Castillo EF, Almazan O. Biofuels: Environment, technology and food security. Renewable and Sustainable Energy Reviews. 2009;13(6):1275-87. doi:10.1016/j.rser.2008.08.014.

2. Vadenbo C, Tonini D, Astrup TF. Environmental multiobjective optimization of the use of biomass resources for energy. Environmental Science \& Technology. 2017;51(6):3575-83. doi:10.1021/acs.est.6b06480.

3. Weng Z, Dai H, Ma Z, Xie Y, Wang P. A general equilibrium assessment of economic impacts of provincial unbalanced carbon intensity targets in China. Resources, Conservation and Recycling. 2018;133:157-68. doi:https://doi.org/10.1016/j.resconrec.2018.01.032.

4. Dong Z, Yang Y, Cai W, He Y, Chai M, Liu B et al. Theoretical analysis of double Logistic distributed activation energy model for thermal decomposition kinetics of solid fuels. Industrial \& Engineering Chemistry Research. 2018;57(23):7817-25. doi:10.1021/acs.iecr.8b01527.

5. Cai J, He Y, Yu X, Banks SW, Yang Y, Zhang X et al. Review of physicochemical properties and analytical characterization of lignocellulosic biomass. Renewable and Sustainable Energy 
Reviews. 2017;76:309-22. doi:https://doi.org/10.1016/j.rser.2017.03.072.

6. Makarfi Isa Y, Ganda ET. Bio-oil as a potential source of petroleum range fuels. Renewable and Sustainable Energy Reviews. 2018;81:69-75. doi:10.1016/j.rser.2017.07.036.

7. Garcia-Nunez JA, Pelaez-Samaniego MR, Garcia-Perez ME, Fonts I, Abrego J, Westerhof RJM et al. Historical developments of pyrolysis reactors: A review. Energy \& Fuels. 2017;31(6):5751-75. doi:10.1021/acs.energyfuels.7b00641.

8. Yu Y, Yang Y, Cheng Z, Blanco PH, Liu R, Bridgwater AV et al. Pyrolysis of rice husk and corn stalk in auger reactor. 1. Characterization of char and gas at various temperatures. Energy \& Fuels. 2016;30(12):10568-74. doi:10.1021/acs.energyfuels.6b02276.

9. Huang L, Ding T, Liu R, Cai J. Prediction of concentration profiles and theoretical yields in lignocellulosic biomass pyrolysis. Journal of Thermal Analysis and Calorimetry. 2015;120(2):1473-82. doi:10.1007/s10973-014-4383-1.

10. Roy P, Dias G. Prospects for pyrolysis technologies in the bioenergy sector: A review. Renewable and Sustainable Energy Reviews. 2017;77:59-69. doi:10.1016/j.rser.2017.03.136. 11. Cai J, Banks SW, Yang Y, Darbar S, Bridgwater T. Viscosity of aged bio-oils from fast pyrolysis of beech wood and Miscanthus: Shear rate and temperature dependence. Energy \& Fuels. 2016;30(6):4999-5004. doi:10.1021/acs.energyfuels.6b00640.

12. Gayubo AG, Valle B, Aramburu B, Montero C, Bilbao J. Kinetic model considering catalyst deactivation for the steam reforming of bio-oil over $\mathrm{Ni} / \mathrm{La}_{2} \mathrm{O}_{3}-\alpha \mathrm{Al}_{2} \mathrm{O}_{3}$. Chemical Engineering Journal. 2018;332:192-204. doi:10.1016/j.cej.2017.09.063.

13. Zhang L, Liu R, Yin R, Mei Y. Upgrading of bio-oil from biomass fast pyrolysis in China: A review. Renewable and Sustainable Energy Reviews. 2013;24:66-72. doi:https://doi.org/10.1016/j.rser.2013.03.027.

14. Rahman MM, Liu R, Cai J. Catalytic fast pyrolysis of biomass over zeolites for high quality bio-oil - $\quad$ A review. Fuel Processing Technology. 2018;180:32-46. 
doi:https://doi.org/10.1016/j.fuproc.2018.08.002.

15. Venderbosch RH. A critical view on catalytic pyrolysis of biomass. Chemsuschem. 2015;8(8):1306-16.

16. Kabir G, Hameed BH. Recent progress on catalytic pyrolysis of lignocellulosic biomass to high-grade bio-oil and bio-chemicals. Renewable and Sustainable Energy Reviews. 2017;70(Supplement C):945-67. doi:10.1016/j.rser.2016.12.001.

17. Várhegyi G, Wang L, Skreiberg $\varnothing$. Towards a meaningful non-isothermal kinetics for biomass materials and other complex organic samples. Journal of Thermal Analysis and Calorimetry. 2018;133(1):703-12. doi:10.1007/s10973-017-6893-0.

18. Wang X, Wang X, Qin G, Chen M, Wang J. Comparative study on pyrolysis characteristics and kinetics of lignocellulosic biomass and seaweed. Journal of Thermal Analysis and Calorimetry. 2018;132(2):1317-23. doi:10.1007/s10973-018-6987-3.

19. Chen T, Li L, Zhao R, Wu J. Pyrolysis kinetic analysis of the three pseudocomponents of biomass-cellulose, hemicellulose and lignin. Journal of Thermal Analysis and Calorimetry. 2017;128(3):1825-32. doi:10.1007/s10973-016-6040-3.

20. Batista R, Jr., Araújo BSA, Franco PIBM, Silvério BC, Danta SC, dos Santos KG. Global reaction model to describe the kinetics of catalytic pyrolysis of coffee grounds waste. Materials Science Forum. 2017;899:173-8. doi:10.4028/www.scientific.net/MSF.899.173.

21. Bu Q, Lei H, Qian M, Yadavalli G. A thermal behavior and kinetics study of the catalytic pyrolysis of lignin. RSC Advances. 2016;6(103):100700-7. doi:10.1039/c6ra22967k.

22. Poddar S, De S, Chowdhury R. Catalytic pyrolysis of lignocellulosic bio-packaging (jute) waste-kinetics using lumped and DAE (distributed activation energy) models and pyro-oil characterization. RSC Advances. 2015;5(120):98934-45. doi:10.1039/c5ra18435e.

23. Li B, Lv W, Zhang Q, Wang T, Ma L. Pyrolysis and catalytic pyrolysis of industrial lignins by TG-FTIR: Kinetics and products. Journal of Analytical and Applied Pyrolysis. 
2014;108(Supplement C):295-300. doi:10.1016/j.jaap.2014.04.002.

24. Lu C, Song W, Lin W. Kinetics of biomass catalytic pyrolysis. Biotechnology Advances. 2009;27(5):583-7. doi:10.1016/j.biotechadv.2009.04.014.

25. Chandrasekaran SR, Kunwar B, Moser BR, Rajagopalan N, Sharma BK. Catalytic thermal cracking of postconsumer waste plastics to fuels. 1. Kinetics and optimization. Energy \& Fuels. 2015;29(9):6068-77. doi:10.1021/acs.energyfuels.5b01083.

26. Vyazovkin S. A time to search: Finding the meaning of variable activation energy. Physical Chemistry Chemical Physics. 2016;18(28):18643-56. doi:10.1039/c6cp02491b.

27. Huang YW, Chen MQ, Luo HF. Nonisothermal torrefaction kinetics of sewage sludge using the simplified distributed activation energy model. Chemical Engineering Journal. 2016;298:154-61. doi:10.1016/j.cej.2016.04.018.

28. Carrier M, Auret L, Bridgwater A, Knoetze JH. Using apparent activation energy as a reactivity criterion for biomass pyrolysis. Energy \& Fuels. 2016;30(10):7834-41. doi:10.1021/acs.energyfuels.6b00794.

29. Cai J, Xu D, Dong Z, Yu X, Yang Y, Banks SW et al. Processing thermogravimetric analysis data for isoconversional kinetic analysis of lignocellulosic biomass pyrolysis: Case study of corn stalk. Renewable and Sustainable Energy Reviews. 2018;82(Part 3):2705-15. doi:10.1016/j.rser.2017.09.113.

30. Yu Y, Fu X, Yu L, Liu R, Cai J. Combustion kinetics of pine sawdust biochar: Data smoothing and isoconversional kinetic analysis. Journal of Thermal Analysis and Calorimetry. 2016;124(3):1641-9. doi:10.1007/s10973-016-5296-y.

31. Cheng YT, Jae J, Shi J, Fan W, Huber GW. Production of renewable aromatic compounds by catalytic fast pyrolysis of lignocellulosic biomass with bifunctional Ga/ZSM-5 catalysts. Angewandte Chemie - International Edition. 2012;51(6):1387-90. doi:10.1002/anie.201107390. 32. Kelkar S, Saffron CM, Li ZL, Kim SS, Pinnavaia TJ, Miller DJ et al. Aromatics from 
biomass pyrolysis vapour using a bifunctional mesoporous catalyst. Green Chemistry. 2014;16(2):803-12. doi:10.1039/C3GC41350K.

33. Cai J, Chen Y. Iterative linear integral isoconversional method: Theory and application. Bioresource Technology. 2012;103(1):309-12. doi:10.1016/j.biortech.2011.10.008.

34. Cai J, Chen S. A new iterative linear integral isoconversional method for the determination of the activation energy varying with the conversion degree. Journal of Computational Chemistry. 2010;30(13):1986-91.

35. Cheng Z, Wu W, Ji P, Zhou X, Liu R, Cai J. Applicability of Fraser-Suzuki function in kinetic analysis of DAEM processes and lignocellulosic biomass pyrolysis processes. Journal of Thermal Analysis and Calorimetry. 2015;119(2):1429-38. doi:10.1007/s10973-014-4215-3. 36. Wu W, Cai J, Liu R. Isoconversional kinetic analysis of distributed activation energy model processes for pyrolysis of solid fuels. Industrial \& Engineering Chemistry Research. 2013;52(40):14376-83. doi:10.1021/ie4021123.

37. Schutyser W, Renders T, Van den Bosch S, Koelewijn SF, Beckham GT, Sels BF. Chemicals from lignin: An interplay of lignocellulose fractionation, depolymerisation, and upgrading. Chemical Society Reviews. 2018;47(3):852-908. doi:10.1039/C7CS00566K.

38. Gillet S, Aguedo M, Petitjean L, Morais ARC, da Costa Lopes AM, Lukasik RM et al. Lignin transformations for high value applications: towards targeted modifications using green chemistry. Green Chemistry. 2017;19(18):4200-33. doi:10.1039/C7GC01479A.

39. Zhang Z, Huber GW. Catalytic oxidation of carbohydrates into organic acids and furan chemicals. Chemical Society Reviews. 2018;47(4):1351-90. doi:10.1039/C7CS00213K.

40. Nolte MW, Shanks BH. A perspective on catalytic strategies for deoxygenation in biomass pyrolysis. Energy Technology. 2017;5(1):7-18. doi:10.1002/ente.201600096.

41. Carlson TR, Cheng Y-T, Jae J, Huber GW. Production of green aromatics and olefins by catalytic fast pyrolysis of wood sawdust. Energy \& Environmental Science. 2011;4(1):145-61. 
doi:10.1039/C0EE00341G.

42. Vispute TP, Zhang H, Sanna A, Xiao R, Huber GW. Renewable chemical commodity feedstocks from integrated catalytic processing of pyrolysis oils. Science. 2010;330(6008):1222-7. doi:10.1126/science.1194218.

43. Li H, Fang Z, Smith RL, Jr., Yang S. Efficient valorization of biomass to biofuels with bifunctional solid catalytic materials. Progress in Energy and Combustion Science. 2016;55:98194. doi:10.1016/j.pecs.2016.04.004.

44. Yung MM, Stanton AR, Iisa K, French RJ, Orton KA, Magrini KA. Multiscale evaluation of catalytic upgrading of biomass pyrolysis vapors on Ni- and Ga-modified ZSM-5. Energy \& Fuels. 2016;30(11):9471-9. doi:10.1021/acs.energyfuels.6b01866.

45. Hoff TC, Gardner DW, Thilakaratne R, Wang K, Hansen TW, Brown RC et al. Tailoring ZSM-5 zeolites for the fast pyrolysis of biomass to aromatic hydrocarbons. ChemSusChem. 2016;9(12):1473-82. doi:10.1002/cssc.201600186.

46. Saha B, Reddy PK, Chowlu ACK, Ghoshal AK. Model-free kinetics analysis of nanocrystalline HZSM-5 catalyzed pyrolysis of polypropylene (PP). Thermochimica Acta. 2008;468(1-2):94-100. doi:10.1016/j.tca.2007.12.004.

47. Saha B, Ghoshal AK. Model-free kinetics analysis of ZSM-5 catalyzed pyrolysis of waste LDPE. Thermochimica Acta. 2007;453(2):120-7. doi:10.1016/j.tca.2006.11.012.

48. Vyazovkin S. On the phenomenon of variable activation energy for condensed phase reactions. New Journal of Chemistry. 2000;24(11):913-7. doi:10.1039/b004279j.

49. Wu W, Mei Y, Le Z, Liu R, Cai J. Effective activation energies of lignocellulosic biomass prolysis. Energy \& Fuels. 2014;28(6):3916-23. doi:10.1021/ef5005896.

50. Wu W, Mei Y, Zhang L, Liu R, Cai J. Kinetics and reaction chemistry of pyrolysis and combustion of tobacco waste. Fuel. 2015;156(Supplement C):71-80. doi:10.1016/j.fuel.2015.04.016. 
51. Belyi VA, Udoratina EV, Kuchin AV. Kinetics of the thermocatalytic conversion of lignocellulose. Kinetics and Catalysis. 2015;56(5):663-9. doi:10.1134/S002315841505002X. 